\title{
Gümüşhane Merkez ve Merkeze Bağlı Bahçecik Köyü Su Kaynaklarının Radyoaktivitesinin Tayini
}

\author{
Ali KAYA $^{1 *}$, Salih Mustafa KARABIDAK ${ }^{1}$, Selim KAYA ${ }^{1}$ \\ ${ }^{1}$ Gümüşhane Üniversitesi, Mühendislik ve Doğa Bilimleri Fakültesi, Fizik Mühendisliği Bölümü, TR-29100, \\ Gümüşhane, Türkiye
}

Geliș tarihi/Received 07.07.2015

Düzeltilerek geliş tarihi/Received in revised form 15.12.2015

Kabul tarihi/Accepted 25.12.2015

\begin{abstract}
$\ddot{\text { Ozet }}$
Bu araştırmada, Gümüşhane ili Bahçecik köyü yayla bölgesi, Gümüşhane merkez ve merkeze bağll Bahçecik köyü şebeke sularının radyoaktivitesinin belirlenmesi amaçlanmıştır. Bu çalışma, içme suyu olarak kullanılan kaynak suların insan sağllğına zararlı miktarda radyoaktivite taşıyıp taşımadı̆̆ının belirlenmesi ve Bahçecik köyü yayla bölgesine yapılacak içme suyu barajından Gümüşhane ili içme suyunun karşılanmasının planlanması bakımından önemlidir. Çalışmada, bölgedeki kaynak sularından alınan numunelerin toplam Alfa-Beta analizleri Türkiye Atom Enerjisi Kurumu İstanbul Küçükçekmece'deki araştırma merkezine gönderilerek orada yapılmıştır. Gama analizleri ise Üniversitemiz laboratuvarlarında yapılmıştır. Elde edilen sonuçlar toplam Alfa Bahçecik yayla bölgesinde en düşük ve en yüksek; $<10 \mathrm{mBq} / \mathrm{L}$ ve $<20 \mathrm{mBq} / \mathrm{L}$ toplam Beta da $13 \pm 1$ $\mathrm{mBq} / \mathrm{L}$ ve $50 \pm 10 \mathrm{mBq} / \mathrm{L}$ belirlenmiştir. Bahçecik köyünde çeşmede toplam Alfa $40 \pm 10 \mathrm{mBq} / \mathrm{L}$ ve şebeke suyunda $<10 \mathrm{mBq} / \mathrm{L}$ toplam Beta çeşmede $70 \pm 10 \mathrm{mBq} / \mathrm{L}$ ve şebeke suyunda $50 \pm 10 \mathrm{mBq} / \mathrm{L}$ olarak belirlenmiştir. Gümüşhane merkez şebeke suyunda ise iki noktadan alınan numuneler için toplam Alfa değerleri sirasiyla $30 \pm 10 \mathrm{mBq} / \mathrm{L}$ ve $40 \pm 10 \mathrm{mBq} / \mathrm{L}$ ve toplam Beta değerleri $112 \pm 10$ $\mathrm{mBq} / \mathrm{L}$ ve $118 \pm 10 \mathrm{mBq} / \mathrm{L}$ olarak belirlenmiştir. Analiz sonuçlarında belirlene toplam Alfa-Beta

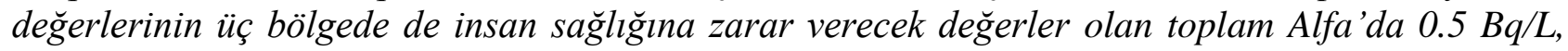
toplam Beta'da 1 Bq/L'nin altında olduğu görülmektedir. Gama analizinden elde edilen sonuçlara göre, ${ }^{226} \mathrm{Ra}$ için $4.6 \mathrm{mBq} / \mathrm{L}$ ile $5.5 \mathrm{mBq} / \mathrm{L},{ }^{232} \mathrm{Th}$ için $2.1 \mathrm{mBq} / \mathrm{L}$ ile $3.6 \mathrm{mBq} / \mathrm{L} ;{ }^{40} \mathrm{~K}$ içinde 91.25 $\mathrm{mBq} / \mathrm{L}$ ile $117.9 \mathrm{mBq} / \mathrm{L}$ aralığında olduğu belirlenmiştir. Bu değerler için hesaplanan yıllık etkin doz eşdeğerleri, Dünya Sağlık Örgütünün (WHO) içme suları için belirlediği yıllık etkin doz eşdeğerinin üst sınırı olan $0.100 \mathrm{mSv} / y$ 'in çok altındadır. Gümüşhane ili şebeke suyu, Bahçecik köyü şebeke suyu ve Bahçecik köyü yayla bölgesindeki doğal su kaynaklarının insan sağlığına zarar verecek derecede radyoaktivite taşımadiğı tespit edilmiştir.
\end{abstract}

Anahtar Kelimeler: Bahçecik Köyü, Gümüşhane, Radyoaktivite Tayini, Su Kaynakları

\section{Radioactivity Measurement of Natural Water Sources In the Area of Bahçecik Village/Gümüşhane-Turkey}

\begin{abstract}
This research aimed to assess radioactivity levels in tap water of Gümüşhane city, the Bahçecik village of Gümüşane and the spring waters in the upland area of the village. It is important to find out if the radioactivity levels of the drinking water springs of this region constitute a public health hazard since a drinking water reservoir is planned for the city of Gümüshane from these sources. The aggregate Alpha-Beta analysis of collected samples from local water sources have been done
\end{abstract}

\footnotetext{
*Ali KAYA, alikaya@gumushane.edu.tr, Tel: (0536) 6939822
} 
at The Küçükçekmece Atom Energy Institute of Turkey in İstanbul. The Gamma analysis has been done at the laboratories of Gumushane University. The obtained results showed that the lowest Alpha value in Bahçecik upland water springs was $<10 \mathrm{mBq} / \mathrm{L}$ and the highest Alpha value was $<20$ $\mathrm{mBq} / \mathrm{L}$ while the total Beta level was determined as $13 \pm 1 \mathrm{mBq} / \mathrm{L}$ and $50 \pm 10 \mathrm{mBq} / \mathrm{L}$. Total Alpha in the village fountain of Bahçecik has been determined as $40 \pm 10 \mathrm{mBq} / \mathrm{L}$ and in village tap water as $<10 \mathrm{mBq} / \mathrm{L}$, while total Beta of samples from the village fountain has been found as $70 \pm 10 \mathrm{mBq} / \mathrm{L}$ and from the village tap water as $50 \pm 10 \mathrm{mBq} / \mathrm{L}$. Samples which were obtained from two points of Gümüşhane city tap water indicated total Alpha values of $30 \pm 10 \mathrm{mBq} / \mathrm{L}$ and $40 \pm 10 \mathrm{mBq} / \mathrm{L}$ while total Beta values were $112 \pm 10 \mathrm{mBq} / \mathrm{L}$ and $118 \pm 10 \mathrm{mBq} / \mathrm{L}$ each. The analysis showed that total Alpha and Beta values which have been found throughout all three local points in the area were below the levels of constituting a threat to human health. According to the results obtained from gamma analysis for Radium $4.6 \mathrm{mBq} / \mathrm{L}$ to $5.5 \mathrm{mBq} / \mathrm{L}$, Thorium to $2.1 \mathrm{mBq} / \mathrm{L}$ to $3.6 \mathrm{mBq} / \mathrm{L}$; Potassium in $91.25 \mathrm{mBq} / \mathrm{L}$ to $117.9 \mathrm{mBq} / \mathrm{L}$ was determined to be in range. The annual effective dose levels that have been calculated for these values are far below the annual effective reference dose levels of $0.100 \mathrm{mSv} / \mathrm{y}$ as determined by the World Health Organization. It has been found that radioactivity levels in Gümüşhane city tap water, in Bahçecik village tap water, and in the natural spring sources of Bahçecik village upland area are below the limits of constituting a health hazard for the public.

Keywords: Bahçecik Village, Gümüşhane, Radioactivity Measurement, Water Sources.

\section{Giriş}

Su için kirletici özellik taşıyan ve dolayısıyla insan sağlığını etkileyen faktörlerden biri de radyasyondur. İnsan sağlığını etkileyen ve çevre kirliliği oluşturan radyasyon su kaynaklarına dört farklı yolla karışmaktadır. Bunlar; toprak ve atmosferde bulunan doğal radyoaktif elementler, nükleer silah denemeleri, radyoaktif atıkların çevresel ortamlara rastgele atılması ve reaktör kazalarıdır.

Dünyanın oluşumuyla birlikte tabiatta yerini alan çok uzun ömürlü radyoaktif elementler yaşadığımız çevrede normal ve kaçınılmaz olarak kabul edilen doğal bir radyasyon düzeyi oluşturmuşlardır. $\mathrm{Bu}$ nedenle, insanoğlu var oluşundan bu yana sürekli radyasyonla iç içe yasamak zorunda kalmıştır. Geçtiğimiz yüzyılda bu doğal düzey, nükleer denemeler ve bazı teknolojik ürünlerin kullanımı ile bir hayli artış göstermiştir.

Yer kabuğu içindeki radyoaktif elementlerin difüzyonu sonucu, kütleler radyoaktif özellik kazanır. Yer altı suları veya yerin derinliklerinden gelen sular içerisinden geçtikleri kayaçlardaki radyoaktif maddelerin etkisiyle bir miktar radyoaktivite kazanır. Yer altı sularında rastlanan en önemli radyoaktif elementler $\mathrm{K}^{40}, \mathrm{Rb}^{87}, \mathrm{Th}^{232}, \mathrm{U}^{235}$ ve $\mathrm{U}^{238}$ dir (Davis ve DeWiest, 1966; Şahinci, 1991).

İnsanların maruz kaldıkları doğal radyasyon seviyesinin büyüklüğünü belirleyen birçok etken vardır. Yaşanılan yer, bu yerin toprak yapıs1, barınılan binada kullanılan malzemeler, mevsimler, kutuplara olan uzaklık, hava şartları, tüketilen besinler ve su bu nedenlerden bazılarıdır. Yağmur, kar, alçak basınç, yüksek basınç ve rüzgâr yönü gibi etkenler de doğal radyasyon seviyesinin büyüklüğünü etkileyen faktörlerdir. Doğal radyasyonlar, uzaydan gelen kozmik isinlar ile kaya, toprak, su ve havada bulunan doğal radyoaktif çekirdeklerin radyoaktif bozunuma uğramaları sonucu yayınlanan ışınlardan ibarettir. Radyasyon çevreye bu doğal kaynaklardan yayılmaktadır. İnsan, içinde yaşadığı doğal çevrede bulunan bu kaynaklardan yayınlanan değişik tipteki radyasyonlara her an maruz kalmaktadır. Radyasyon dozu değerlendirilmelerinde doğal kaynaklar oldukça önemli yer tutarlar. Çünkü insanlar hayatları süresince doğal kaynaklardan yayınlanan radyasyonlardan belli oranlarda doz almaktadırlar. Yillar boyunca alınan bu radyasyon, bir süre sonra vücutta belirli tahribatlara yol açabilmekte, 
hatta bu tahribatlar ölümle sonuçlanabilmektedir. Radyasyon doz değerleri insanların yıllık kullandıkları su miktarlarına göre aldıkları radyasyon oranını gösteren yıllık doz eşdeğerleri yetişkinler, çocuklar ve bebekler için hesaplanır. Bunun nedeni insanın bu çağlarda günlük kullandığ 1 ortalama su ihtiyacının farklı miktarlarda olmasıdır. İnsan sağlığı açısından içme sularında Dünya sağlık örgütü (WHO) (2003) tarafından belirlenen değerler toplam Alfa 0.5 $\mathrm{Bq} / \mathrm{L}$, toplam Beta $1 \mathrm{~Bq} / \mathrm{L}$ ve y1llik etkin doz eşdeğer sınırı da $0.1 \mathrm{mSv} / \mathrm{y} ı 1 d ı r$ (Doğan, 2015).

Çevresel radyasyon ölçümlerindeki temel amaç, insanların çevresel kaynaklardan aldıkları radyasyon türü ile dozunun belirlenmesi ve oluşturacağı riskin değerlendirilmesidir. Bunun için de, doğal radyasyon kaynaklarını oluşturan radyonükloidlerin çevresel ortamdaki konsantrasyonları ile radyasyonun özellikle insanda olmak üzere, biyolojik sistemler üzerindeki tesirinin tayin edilmesi gerekir. Sulardaki doğal radyoaktivite seviyesinin belirlenmesi ile ilgili çalışmalar başlangıçta sadece kaplıca sularında yapılmaktaydı. Çünkü yer altı sularının radyoaktivite konsantrasyonu yüzey sularına göre daha fazladır. Son yıllarda yapılan çalışmalarda içme sularında da doğal radyonüklit bulunduğu ortaya çıkmıştır. Yer altı sularında çoğunlukla uranyum serisi elemanlarından radyum ve radon bulunmaktadır. ${ }^{226} \mathrm{Ra}$ 'nın bozunma ürünü olan radyoaktif radon, bazı yer altı sularında oldukça yüksek konsantrasyonlarda bulunur. Yer altı sularında bulunan aktinyum serisi elemanlarını tespit etmek oldukça zordur. Baz1 sularda toryum serisinden ${ }^{232} \mathrm{Th}$ ve ${ }^{226}$ Ra'nın dedekte edilebilecek miktarda bulunmasına rağmen, yine bu seriden olan ${ }^{220} \mathrm{Rn}$ 'in, çok kısa yarı ömre sahip olması su ve kayalarda birikmesine olanak sağlamamaktadır (Özger, 2005; Gören, 2011). Toplam Alfa aktivitesi doğal sularda Toryum çözünürlüğünün düşük olmasından dolayı genellikle Uranyum ve Radyum izotoplarından kaynaklanmaktadır (Osmond and Ivanovich, 1992). Prensip olarak Alfa aktivitesinin ana nedeni ${ }^{226} \mathrm{Ra}$ olmasina rağmen, bazen ${ }^{232} \mathrm{Th},{ }^{210} \mathrm{Po}$ veya ${ }^{224} \mathrm{Ra}$ katkıda bulunduğu belirtilmektedir (Blanchard et al., 1985). Bunun gibi, Beta aktivitesinin esas olarak ${ }^{40} \mathrm{~K}$ ve ${ }^{228} \mathrm{Ra}$ neden olduğu belirtilmektedir (Damla ve diğ., 2006). Doğal sularda bulunan en önemli radyoaktif maddeler uranyum, toryum, potasyum, radyum ve radon olduğu belirtilmektedir (Bakaç ve Kumru, 1999).

Ayrıca çevresel ortamda bulunan radyonükloidler ile insanların bu kaynaklardan aldıkları radyasyon dozu arasındaki ilişkinin de belirlenmesi gerekir. Ancak böyle bir araştırmadan sonra bir bölgenin doğal radyasyon açısından sağlıklı yasamaya uygun olup olmadığına karar verilebilir (Bakaç, 1998) $\mathrm{Bu}$ alanda yurt içi ve yurt dişında araştırma çalışmaları yapılmaktadır (Ahmed, 2004; Gültekin ve Dilek 2005; Damla, 2006; Damla, Çevik, Karahan ve Kobya., 2006; Damla, Çevik, Karahan, Kobya, Kocak ve Işık, 2009; Kopya, 2009). Damla 2006 da Doğu Karadeniz Bölgesinde yirmi yedi noktadan örnekler kullanarak içme sularında toplam Alfa ve Beta değerlerini belirleme çalışması yürütmüştür. Bu çalışmada, toplam Alfanın minimum değerinin $0.2 \mathrm{mBq} / \mathrm{L}$ (Fındıklı) ve maksimum değerinde $15 \mathrm{mBq} / \mathrm{L}$ (Ardeşen) ve Toplam Beta değerlerinin minimum $25.2 \mathrm{mBq} / \mathrm{L}$ (Arhavi) ve maksimum $264.4 \mathrm{mBq} / 1$ (Giresun) olduğu belirlenmiştir. Kopya'nın 2009 da Gümüşhane ili geneline yedi farklı kaynaktan aldıkları numunelerle yaptığı çalışmada minimum toplam Alfa değerin $11 \mathrm{mBq} / \mathrm{L}$ maksimum değerin 188 $\mathrm{mBq} / \mathrm{L}$ ve ortalama değerin $66 \mathrm{mBq} / \mathrm{L}$ olduğunu belirlemişlerdir. Gültekin ve Dilek 2005'de Gümüşhane'de mineralli su kaynakları ile ilgili yürüttükleri çalışmada; Mineralli su kaynaklarında toplam Alfa aktivitelerinin $122-780 \mathrm{mBq} / \mathrm{L}$, arasinda değiştiği belirlemişlerdir. $\mathrm{Bu}$ amaçla araştırmalar; Uluslararası Radyolojik Korunma Komisyonu (ICRP), Amerika Birleşik Devletleri Radyasyon Korunması ve Ölçümü Milli Komitesi (UNSCEAR) ve Türkiye Atom Enerjisi Kurumu Çekmece Nükleer Araştırma ve Eğitim Merkezi (TAEK-ÇNAEM) gibi milli ve uluslararası kuruluşlar tarafindan yapılmakta ve desteklenmektedir. 
Bu çalışma, bölgedeki doğal kaynak sularında doğal radyoaktivite seviyelerinin belirlenmesi konusunda önceden araştırma yapılmamış olması ve araştırma yapılan Bahçecik köyü yayla bölgesin de yapılması planlanan bir baraj ile Gümüşhane il merkezinin içme suyunun karşılanmasının düşünülmesi bakımından önemlidir. Ayrıca, ülkemiz ve bölge hem coğrafik yapısı hem de komşu ülkelerde kurulmuş nükleer santraller sebebiyle sürekli radyoaktif kirliliğe maruz kalma riski ile karşı karşıyadır. Bu nedenle, dünya üzerindeki önemi giderek artan ve $A B$ 'ne giriş sürecinde olan ülkemizde doğal radyasyon düzeylerinin belirlenmesi gerekmektedir. $\mathrm{Bu}$ araștırma ile Gümüşhane ili Bahçecik Köyü Yayla bölgesindeki doğal su kaynaklarının, Bahçecik köyü ve Gümüşhane ili merkezinde ki içme sularının radyoaktivitelerinin belirlenmesi amaçlanmiştır.

\section{Materyal ve Yöntem}

$\mathrm{Bu}$ araştırmanın yürütülmesindeki aşağıdaki işlem basamakları takip edilmiştir.

\subsection{Numune Alınacak Yerlerin Belirlenmesi}

Bahçecik köyü yayla bölgesinde dört kaynaktan, Bahçecik köyünde şebeke içme suyu ve bir çeşmeden; Gümüşhane il merkezinde iki farklı noktada içme suyu şebekesinden numuneler alınmıştır.

\subsection{Numunelerin Toplanmast}

Bahçecik köyü yayla bölgesinden dört, Bahçecik köyü ve Gümüşhane merkez den ikişer kaynaktan yapılacak ölçümlere uygun olarak her kaynaktan Gama analizi için yirmi ve Toplam Alfa-Beta analizleri için de ikişer litre örnekler alınmıştır. Numune toplama işleminde, örnek alımı direkt olarak suyun kaynağına ulaşılarak yapılmış, numunelerin koyuldukları kaplar ise steril su ile yıkanarak ve alınacak su ile bir miktar doldurulup çalkalandıktan sonra boşaltılıp dolum işlemi gerçekleştirilmiştir. Böylece, dışarıdan istenmeyen herhangi bir katkının gelmesi mümkün olduğunca önlenmeye çalış1lmıştır.

\subsection{Toplam Alfa ve Toplam Beta Radyo- aktiflik Ölçümleri}

\subsubsection{Numunelerin Toplam Alfa, Beta Analizine Hazırlanması}

Numuneler laboratuvara getirilerek litre başına iki damla nitrik asit damlatılarak ağzı sıkıca kapatıldıktan sonra etiketlenerek koruma altına alınmıştır. Bunun nedeni, su örnekleri içerisindeki elementlerin partiküler hale gelerek tortu oluşturmasını ve örnek kabının çeperlerine yapıșmasını önlemektir. $\mathrm{Bu}$ şekilde paketlenen numuneler ÇNAEM araştırma laboratuvarına götürülmüştür.

Burada her bir numune çeker ocakta (hot plate) $500 \mathrm{~mL}$ 'lik beherlere konarak $60^{\circ} \mathrm{C}$ ' de yaklaşık $100 \mathrm{~mL}$ kalana kadar buharlaştırılmıştır. Kalan kısım darası alınmış $20 \mathrm{~cm}^{3}$ 'lük paslanmaz çelik kaplara (planset) azar azar taşmayacak şekilde aktarılmıştır. Su tamamen buharlașinca plansetler bir desikatörde oda 1sısına getirilip hassas terazide tartılıp ve tortu (rezidü) miktarı tayin edilmiştir. Sayımlarda, özellikle alfa sayımlarında tortu miktarı çok önemlidir. Tortu miktarı 400 mg'1 geçmemelidir, aksi takdirde alfa parçacıklarında selfabsorpsiyon oluşmakta bu da analiz sonuçlarında hatalara neden olmaktadır. Daha sonra çelik kaplar $105^{\circ} \mathrm{C}$ sıcaklığındaki bir etüv firını içine konularak iyice kurutulmuştur. Ardından bütün numuneler toplam Alfa ve toplam Beta aktiflikleri tayin edilmek üzere detektöre konularak 500 dakika süreyle sayılmıștır.

\subsubsection{Deney Sistemi}

Numunelerin toplam Alfa ve toplam Beta radyoaktiflik analizleri için, ÇNAEM Sağlik Fiziği Bölümü Laboratuvarı'nda bulunan Berthold marka LB770 model 10 kanallı düşük seviyeli alfa-beta sayım cihazı kullanılmıştır. $\mathrm{Bu}$ cihaz, 10 numunenin alfa ve beta sayımlarını (radyoaktivite ölçümlerini) aynı anda yapabilecek şekilde tasarlanmıştır. Dedüksiyon ortamı ve elektronik devre olmak üzere başlıca iki kısımdan meydana gelir. 


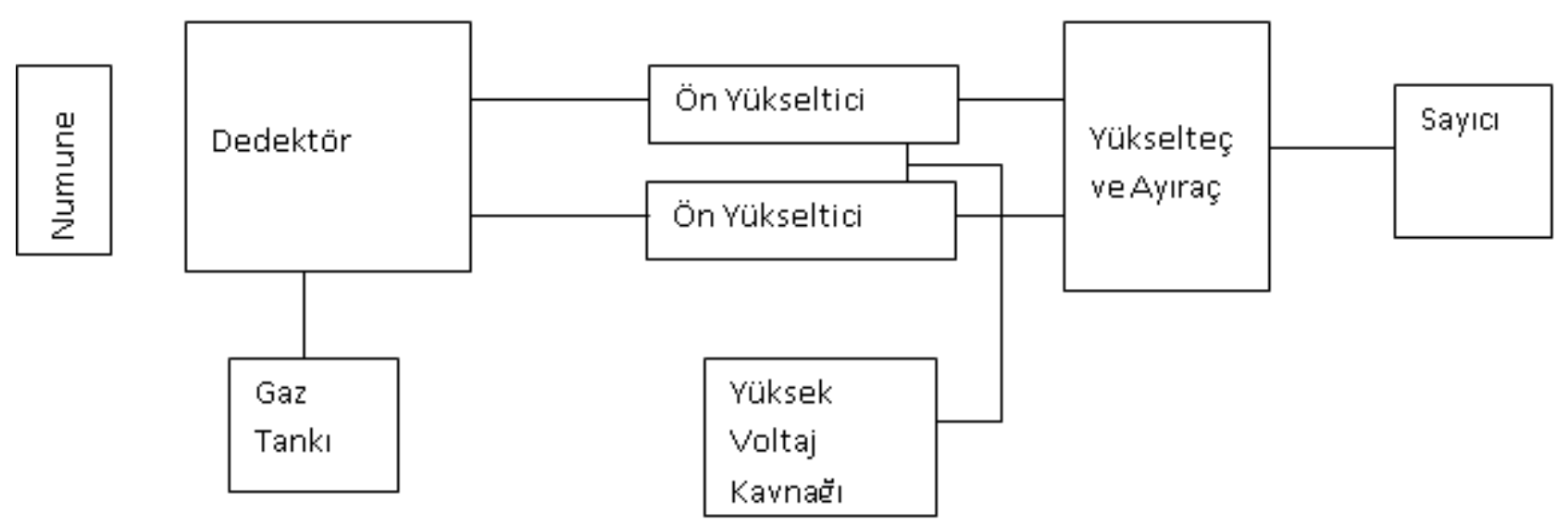

Şekil.1. Toplam Alfa ve Beta sayım cihazının blok diyagramı

Toplam Alfa ve Beta sayım cihazının blok diyagramı dedüksiyon ortamı olarak en çok kullanılan gazlar argon, ksenon, izobütan, helyum ve metandır. Bir tüp, bu gazlardan biri veya ikisinin karışımı ile doldurulup içine iki elektrot konulur. Gaz içinde meydana gelen iyonlar zit işaretli elektrotlarda toplanırlar. İyonların elektrotlarda toplanmasindan meydana gelen elektrik akımı laboratuvar sayım cihazının elektronik devresinde sayılır.

Alfa veya Beta sayımında kullanılan bu gaz akışlı orantılı sayıcılar genellikle yarım küre seklinde bir sayım odasına sahiptir. Ortalarında tungstenden yapılmış bir tel halka bulunur. Tel, anot görevi, oda duvarları da katot görevi görür. Akışkan gaz, oda içinden geçirilerek oda içinde pozitif iyonlar oluşturulur. Detektörün çalışma voltajı 1650 $\mathrm{V}$ olup çap1 5 cm'dır. $\mathrm{Bu}$ sayıcılarda kullanılan akışkan gaz \%90 argon ve \%10 metan karışımı içermektedir (Damla, 2006).

\subsection{Gama Spektroskopisi Ölçümleri}

\subsubsection{Numunelerin Gama Spektroskopisi Analizine Hazırlanması}

Belirlenmiş olan bölgelerden 20'er litre su alınarak daha önceden steril hale getirilmiş plastik şişelere doldurulmuştur. $\mathrm{Su}$ numuneleri 15 L'lik temiz cam beherlere aktarılarak, $50-60^{\circ} \mathrm{C}$ 'lik bir 1sitıcı üzerine buharlaşmaya bırakılmıştır. 1-2 hafta süreyle su miktarları $100 \mathrm{~mL}$ kalana kadar buharlaştırmaya devam edildi. Buharlaşma esnasında beher cidarlarına yapışan maddeleri önlemek için beher içeresine birkaç damla $\mathrm{HCl}$ katılmıştır.

Sonra kalan miktarlar boş sayımları alınmış marinelli kaplarına konularak, iç dengeye gelmeleri için yaklaşık bir ay süreyle bekletildi. Daha sonra sirayla gama spektrometresi cihazında piklerin net olarak görülmesi ve sayım hatalarını azaltmak amacıyla 86400 saniye süreyle sayımlar yapild1.

\subsubsection{Deney Sistemi}

Numunelerin gama spektroskopisi ölçümleri için ORTEC Model 905-4 NaI(Tl) sintilasyon detektörü kullanılmıştır. Detektör, sintilasyon detektörü ve gama 1şınlarının sintilatör ile etkileşmesi sonucu oluşan 1 şı sinyalini elektrik sinyaline çeviren fotomultiplikatör'den oluşmaktadır. Sistemdeki 'dead time' doğruluğu 50000 cps girdi sayım oranına kadar $\% 5$ ten daha az hata vermektedir. $\mathrm{NaI}(\mathrm{Tl})$ dedektörü 1000 voltta çalışmakta ve aynı zamanda detektör taşınabilir (portatif) olarak kullanılabilir özelliğe sahiptir. Ayrıca spektrumlar Maestro for Windows yazılımı kullanılarak elde edilmiştir.

\subsubsection{Gama Spektrumu Analizi ve Aktivitenin Hesaplanması}

Gama spektrumunun analizinde U-238 serisi için Pb-214 (351.9 keV), Bi-214 (609.3 keV) enerjilerindeki, Th-232 serisi için Tl-208 $(583.2 \mathrm{keV}), \quad$ Ac-228 (911.2 $\mathrm{keV})$ 
enerjilerindeki piklerinin alanlarının ortalaması ve $\mathrm{K}-40$ için $1460.8 \mathrm{keV}$ enerjisindeki pikin alanı alınmıştır. $\mathrm{Bu}$ enerjilerdeki alanların seçilmesinin sebebi doğada bulunma yüzdelerinin diğer izotoplara göre daha fazla olmasidır.

Aktivite, aşağıdaki formül ile bulunur:

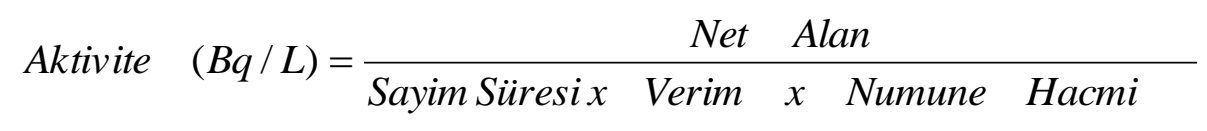

Burada net alan, piklerin altında kalan alandan bos sayım (background) sonucu elde ettiğimiz alanın çıkarılmasıyla bulunur. Net alanın, sayım süresi, detektör verimi ve numune hacminin çarpımına bölümü aktiviteyi verir. Her numune NaI detektöründe 86.400 saniye sayılmıştır.

Radyasyona maruz kalan bir insanda oluşabilecek zararlı biyolojik etkilerin hesaplanabilmesi açısından, ölçülebilen bir radyasyon dozunun eşdeğerine ihtiyaç duyulmaktadır. $\mathrm{Bu}$ nedenle sivil halkın ve radyasyonla çalışanların aldığ dozu için standartlar, belirli zamanlarda ifade edilirler.

$\mathrm{Su}$ numunelerinden alınan yıllık etkin doz eşdeğerleri aşağıdaki bağıntıdan bulunur (Kopya, 2009).

$\mathrm{D}=\mathrm{C}_{\mathrm{R}} \cdot \mathrm{I}_{\mathrm{A}} \cdot \mathrm{E}_{\mathrm{D}}$

Burada $\mathrm{D}$, y1llık etkin doz eşdeğeri $(\mu \mathrm{Sv} / \mathrm{y})$ olmak üzere, $C_{R}$ yıllık tüketilen su miktarı $(\mathrm{L} / \mathrm{y} 1), \mathrm{I}_{\mathrm{A}}$, radyoaktif çekirdeğin aktivitesi $(\mathrm{mBq} / L)$ ve $\mathrm{E}_{\mathrm{D}}$, doz katsayısı $(\mathrm{mSv} / \mathrm{Bq})^{\prime}$ dır. $\mathrm{Bu}$ hesaplamalarda doğal kaynak suları için günlük içim miktarının yetişkinlerde $2 \mathrm{~L}$, çocuklarda yaklaşı 1Lve bebeklerde ise yaklaşık $0.75 \mathrm{~L}$ olduğu kabul edilmiştir (Kopya, 2009; Chau and Michalec, 2008).

\section{Bulgular}

Araştırma kapsamında sekiz kaynaktan alınan numunelerin toplam Alfa-Beta değerleri aşağıda Tablo 2'de verilmiştir.
Tablo 1. Bazı radyoaktif çekirdeklerin doz katsayıları (WHO, 2003)

\begin{tabular}{|c|c|}
\hline $\begin{array}{c}\text { Radyoaktif } \\
\text { çekirdek }\end{array}$ & $\begin{array}{c}\text { Doz Katsayıs1 } \\
(\mathrm{mSv} / \mathrm{Bq})\end{array}$ \\
\hline${ }^{238} \mathrm{U}$ & $4.5 \times 10^{-5}$ \\
\hline${ }^{226} \mathrm{Ra}$ & $2.810^{-4}$ \\
\hline${ }^{232} \mathrm{Th}$ & $2.3 \times 10-4$ \\
\hline${ }^{228} \mathrm{Ra}$ & $6.9 \times 10^{-4}$ \\
\hline${ }^{134} \mathrm{Cs}$ & $1.9 \times 10^{-5}$ \\
\hline${ }^{137} \mathrm{Cs}$ & $1.3 \times 10^{-5}$ \\
\hline${ }^{131} \mathrm{I}$ & $2.2 \times 10^{-5}$ \\
\hline${ }^{214} \mathrm{Bi}$ & $1.1 \times 10^{-7}$ \\
\hline${ }^{214} \mathrm{~Pb}$ & $1.4 \times 10^{-7}$ \\
\hline${ }^{40} \mathrm{~K}$ & $6.2 \times 10^{-6}$ \\
\hline${ }^{222} \mathrm{Rn}$ & $6 \times 10^{-6}$ \\
\hline
\end{tabular}

Tablo. 2. Toplam Alfa Beta değerleri

\begin{tabular}{|c|c|c|}
\hline $\begin{array}{c}\text { Numune } \\
\text { kodu }\end{array}$ & $\begin{array}{c}\text { Toplam Alfa } \\
(\mathrm{mBq} / \mathrm{L})\end{array}$ & $\begin{array}{c}\text { Toplam Beta } \\
(\mathrm{mBq} / \mathrm{L})\end{array}$ \\
\hline BKYM & $<10$ & $30 \pm 10$ \\
\hline BKYK & $<20$ & $50 \pm 10$ \\
\hline BKYS & $<20$ & $13 \pm 1$ \\
\hline BKYA & $<10$ & $30 \pm 10$ \\
\hline BKÇE & $40 \pm 10$ & $70 \pm 10$ \\
\hline BKŞS & $<10$ & $50 \pm 10$ \\
\hline GMKŞ & $30 \pm 10$ & $118 \pm 10$ \\
\hline GMHM & $40 \pm 10$ & $112 \pm 10$ \\
\hline
\end{tabular}

Tabloda görüldüğü gibi, Toplam alfa en düşük $<10 \mathrm{mBq} / \mathrm{L}$ ile en yüksek $40 \pm 10$ $\mathrm{mBq} / \mathrm{L}$ değerleri arasında yer almaktadır. Toplam Beta ise en düşük $13 \pm 1 \mathrm{mBq} / \mathrm{L}$ ile en yüksek $118 \pm 10 \mathrm{mBq} / \mathrm{L}$ değerleri arasında yer almaktadır. 
Araştırma kapsamında sekiz kaynaktan alınan numunelerin Gama değerlerinin aşağıda Tablo 3 'de verilmiştir.

Tablo 3'de görüldüğü gibi, Ra-226 en düşük $4.6 \mathrm{mBq} / \mathrm{L}$ ile en yüksek $5.5 \mathrm{mBq} / \mathrm{L}$, Th-232 en düşük $2.1 \mathrm{mBq} / \mathrm{L}$ ile en yüksek $3.6 \mathrm{mBq} / \mathrm{L}$ ve $\mathrm{K}-40 \mathrm{mBq} / \mathrm{L}$ en düşük $94.59 \mathrm{mBq} / \mathrm{L}$ ile en yüksek $117.9 \mathrm{mBq} / \mathrm{L}$ değerleri arasında yer almaktadır.

Numunelerin yıllık etkin doz eşdeğerlerinin ortalamaları yetişkinler, çocuklar ve bebekler için tespit edilerek Tablo 4'de verilmiştir.

Tablo. 3. Seçilen kaynaklarda ${ }^{226} \mathrm{Ra},{ }^{232} \mathrm{Th}$ ve ${ }^{40} \mathrm{~K}$ değerleri

\begin{tabular}{|l|c|c|c|}
\hline & Ra-226(mBq/L) & Toryum-232 $(\mathrm{mBq} / \mathrm{L})$ & K-40 $(\mathrm{mBq} / \mathrm{L})$ \\
\hline BKYM & 4.7 & 3.2 & 106.8 \\
\hline KKYK & 5.2 & 2.1 & 113.5 \\
\hline BKYS & 5.1 & 3.1 & 117.9 \\
\hline BKYA & 5.5 & 3.6 & 111.3 \\
\hline BKÇE & 4.6 & 2.7 & 92.4 \\
\hline BKŞS & 5.1 & 2.3 & 91.25 \\
\hline GMKȘ & 4.8 & 2.9 & 94.59 \\
\hline GMHM & 4.6 & 2.9 & 94.59 \\
\hline
\end{tabular}

Tablo 4. Numunelerin yıllık etkin doz eşdeğerlerinin ortalamaları

\begin{tabular}{|l|c|c|c|}
\hline Yaş Gruplar1 & \multicolumn{3}{|c|}{$\mathrm{D}\left(\mu \mathrm{Sv} \cdot \mathrm{y}^{-1}\right)$} \\
\hline & ${ }^{226} \mathrm{Ra}\left(\mu \mathrm{Sv} \cdot \mathrm{y}^{-1}\right)$ & ${ }^{232} \mathrm{Th}\left(\mu \mathrm{Sv} \cdot \mathrm{y}^{-1}\right)$ & ${ }^{40} \mathrm{~K}\left(\mu \mathrm{Sv} \cdot \mathrm{y}^{-1}\right)$ \\
\hline Yetişkinler & 1.01 & 0.47 & 0.46 \\
\hline Çocuklar & 0.51 & 0.24 & 0.23 \\
\hline Bebekler & 0.38 & 0.18 & 0.17 \\
\hline
\end{tabular}

\section{Tartışma}

Araştırma kapsamında elde edilen bulgulardan toplam Alfa değerleri en düşük $10 \mathrm{mBq} / \mathrm{L}$ den daha düşük Bahçecik köyü yayla bölgesinde birinci ve dördüncü kaynaklarda ve en yüksek değerler ise $40 \pm 10$ $\mathrm{mBq} / \mathrm{L}$ ile Bahçecik köyü çeşme suyu ile Gümüşhane merkez Hasanbey Mahallesi şebeke suyunda ölçülmüştür. Diğger değerler bunların arasında yer almaktadır (Tablo 2). Kopya'nın 2009'da Gümüşhane ili geneline yedi farklı kaynaktan aldıkları numunelerle yaptığı çalışmada minimum toplam Alfa değerin $11 \mathrm{mBq} / \mathrm{L}$ maksimum değerin 188 $\mathrm{mBq} / \mathrm{L}$ ve ortalama değerin $66 \mathrm{mBq} / \mathrm{L}$ olduğu belirlenmiştir. Çalışmamızda doğal su kaynaklarında toplam Alfa değerleri bu araştırmacının elde ettiğ minimumda aynı iken maksimumda düşük olduğu görülmektedir. Bunun nedeni bizim araştırma yaptığımız bölgede alfa değerlerini etkileyen ${ }^{226} \mathrm{Ra},{ }^{232} \mathrm{Th}, \quad{ }^{210} \mathrm{Po}$ veya ${ }^{224} \mathrm{Ra}$ elementlerinin konsantrasyonunun daha az olmasından kaynaklanıyor olabilir (Blanchard et al., 1985). Gültekin ve Dilek 2005'de Gümüşhane'de mineralli su kaynakları ile ilgili yürüttükleri çalışmada mineralli su kaynaklarında toplam Alfa aktivitelerinin 122-780 $\mathrm{mBq} / \mathrm{L}$ arasında değiştiğini belirlemiştir. Görüldüğü gibi mineralli sularda toplam Alfa değerleri doğal kaynak içme sularındaki değerlerden oldukça yüksektir. Toryum ve Uranyum elementi içeren ortamlarla temas eden sularda alfa aktivitesinin yüksek olduğu belirtilmektedir (Gültekin ve Dilek 2005).

Araştırma kapsamında elde edilen bulgulardan toplam Beta değerleri en düşük $13 \pm 1 \mathrm{mBq} / \mathrm{L}$ ile Bahçecik köyü yayla bölgesinde üçüncü kaynakta ve en yüksek değerler ise $118 \pm 10 \mathrm{mBq} / \mathrm{L}$ ile Gümüşhane merkez Kampüs şebeke suyunda ölçülmüştür. 
Diğer değerler bunların arasında yer almaktadir (Tablo 2). Kopya 2009'da Gümüşhane ili genelinde yedi farklı kaynaktan aldıkları numunelerle yaptığı çalışmada minimum toplam Beta değerinin 24 $\mathrm{mBq} / \mathrm{L}$, maksimum değerin $78 \mathrm{mBq} / \mathrm{L}$ ve ortalama değerin $41 \mathrm{mBq} / \mathrm{L}$ olduğunu belirlemiştir. Gültekin ve Dilek 2005 'de Gümüşhane'de mineralli su kaynakları ile ilgili yürüttükleri çalışmada mineralli su kaynaklarında toplam Beta aktivitelerinin 67$401 \mathrm{mBq} / \mathrm{L}$ arasında değiştiğini belirlemişlerdir. Görüldüğü gibi mineralli sularda toplam alfa değerleri yüksektir. Çalışmamızda doğal su kaynaklarında toplam Beta değerleri ile Kopya'nın (2009) değerleri birbirine yakın değerler olduğu görülmektedir.

Gama analizinden elde edilen sonuçlara göre, Radyum için $4.6 \mathrm{mBq} / \mathrm{l}$ ile $5.5 \mathrm{mBq} / \mathrm{L}$, Toryum için $2.1 \mathrm{mBq} / \mathrm{L}$ ile $3.6 \mathrm{mBq} / \mathrm{L}$; Potasyum içinde $91.25 \mathrm{mBq} / \mathrm{L}$ ile 117.9 $\mathrm{mBq} / \mathrm{L}$ aralığında olduğu belirlenmiştir (Tablo 3). Çalışmamızda doğal su kaynaklarında Radyum, Toryum ve Potasyum için elde edilen değerlerin Kopya'nın (2009) yapmış olduğu araştırmadan Gümüşhane merkezi için elde ettiği değerlerle yakın olduğu ancak ilçelerle birlikte elde edilen ortalama değerlerden oldukça düşük olduğu görülmektedir. Buradan Gümüşhane'nin ilçelerinde Gama radyasyonunun merkeze göre yüksek olduğu görülmektedir. Bu sonuçlar Jeolojik formasyon farklılıklarının su kaynakları üzerindeki etkisini ortaya koymaktadır. Özellikle yer altı suları değişik jeolojik oluşumlarla temas halindedir. Bu yer altı formasyonlarının içeriğinde bulunan kimyasal bileşikler suda eriyebilme derecelerine göre yer altı sularına az yada çok oranda karışır. Çözülmüş maddelerin miktarı formasyonlarla yer altı sularının temas süresi, suyun akış hızına ve sıcaklığına, formasyonun cinsine ve ortamın basıncına bağlı olarak değişir. Yer altındaki çeşitli özelliklerde ki jeolojik formasyonların içinde değişik oranlarda radyoaktif maddeler bulunmaktadır. $\mathrm{Bu}$ maddeler magmatik oluşumlarda en fazla miktardadır. Ayrıca kil ve şeyl gibi tortul kitlelerde de radyoaktif maddelere rastlanmaktadır. Kum-çakı1, kumtaşı, çatlaklı kalter gibi akifer özellikteki tortul kütlelerde ise çok az miktarda radyoaktif madde bulunmaktadır. Dolayısıyla doğal radyoaktif maddelerin bulunduğu ortamlardan geçen veya bu ortamlarda bulunan sular radyoaktivite içerir.

Çalışmamız numunelerinde Çernobil nükleer kazası sonucu bölgemizde oluşan ${ }^{137} \mathrm{Cs}$ ye rastlanmamıştır. Bu kaza sonucu oluşan ${ }^{137} \mathrm{Cs}$ araştırma yapilan bölgeye ulaşmadığı veya yarı ömrünü tamamladığından dolayı etkisinin ortadan kalktığı düşünülmektedir.

Gama değerleri için insanların y1llık kullandıkları su miktarlarına göre aldıkları radyasyon oranını gösteren yıllık doz eşdeğerleri yetişkinler, çocuklar ve bebekler için hesaplanmıştır (Tablo 4). Bu değerler Dünya Sağlık Örgütünün (WHO) (2003) içme suları için belirlediği yıllık etkin doz eşdeğerinin üst sınırı olan $0.100 \mathrm{mSv} / \mathrm{y}^{\prime}$ in çok altındadır.

\section{Sonuç-Yorum}

Araştırmanın amacı doğrultusunda Gümüşhane ili merkez Bahçecik köyü Yayla bölgesi, Bahçecik köyünde şebeke suyu ile içme suyu olarak kullanılan bir çeşmeden ve Gümüşhane merkez şebeke suyundan iki farklı mahalleden alınan musluk sularının toplam Alfa, Beta ve Gama analizleri yapılmıştır. Araştırma sonucu elde edilen toplam Alfa - Beta değerleri Dünya Sağlik Örgütü (WHO) ve Türkiye Standartlar Enstitüsü (ITS) insan sağlığı açısından içme suları için belirlediği minimum toplam Alfa $0.5 \mathrm{~Bq} / \mathrm{L}$, toplam Beta $1 \mathrm{~Bq} / \mathrm{L}$ değerlerinden düşük olduğu tespit edilmiştir. Gama radyasyonu için elde edilen tüm yıllık etkin doz eşdeğerlerinin WHO'nun (2003) içme suları için belirlediği yıllık etkin doz eşdeğerinin üst sınırı olan $0.100 \mathrm{mSv} / \mathrm{y}$ değerinin çok altında olduğu tespit edilmiştir.

Araştırma sonucunda radyoaktivitesi belirlenen su kaynaklarının içilmesi ve kullanılmasının insan sağlığı açısından bir tehlike arz etmediği tespit edilmiştir. Benzer çalışmanın Gümüşhane ilinin tamamını kapsayacak şekilde ve diğer iller içinde yapılmasının yararlı olacağı düşünülmektedir. 


\section{Kaynakça}

Agbalagba E. O., Avwiri G. O., and Chadumoren Y. E., June 2013, Gross $\alpha$ and $\beta$ Activity Concentration and Estimation of Adults and Infants Dose intake in Surface and Ground Water of Ten Oil Fields Environment in Western Niger Delta of Nigeria, J. Appl. Sci. Environ. Manage, Vol. 17 (2) 267-277.

Ahmed, N. K., 2004, Natural Radioactivity of Ground and Drinking Water in Some Areas of Upper Egypt, Turkish J. Eng. Env. Sci. 28, 345 -354 .

Bakaç, M., 1998, Gediz Nehri ve Çevresindeki Radyoaktif, Major ve iz Element Seviyelerinin Belirlenerek Faktör Analizi Yöntemi ile incelenmesi, Doktora Tezi, Ege Üniversitesi, Fen Bilimleri Enstitüsü, İzmir.

Bakaç, M. ve Kumru, M. N., 1999, Gediz Havzası Topraklarındaki Doğal Radyoaktivite Seviyesi, Çevre Koruma Dergisi, Cilt 8, Sayı 30, 18-21.

Blanchard, R.L., Hahne, R.M., Kohn, B., McCurdy, D., Mellor, R.A., Moove, W.S., Sedlet, J., Whittaker, E.,. 1985, Radiological sampling and analytical methods for national primary drinking water regulation. Health hys. 48 , 587-600.

Chau, N.D. ve Michalec, B., 2008. Natural Radioactivity in Bottled Natural Spring, Mineral and Therapeutic Waters in Poland, Journal of Radioanalytical and Nuclear Chemistry, 279,1, 121-129.

Damla, N., 2006, Doğu Karadeniz Bölgesindeki İçme Sularında Toplam Alfa, Toplam Beta ve Gama Radyoaktifliği, Yüksek
Lisans Tezi, K.T.Ü. Fen Bilimleri Enstitüsü, Trabzon.

Damla, N., U. Cevik, G. Karahan and Kobya A.I., 2006, Gross alpha and beta activities in tap water in Eastern Black Sea region of Turkey. Chemosphere 62: 957-960.

Damla, N., U. Cevik, G. Karahan, A.I. Kobya, M. Kocak and U. Isik, 2009, Determination of gross alpha and beta activities in water from Batman, Turkey. Desalination, 244: 208-214.

Davis, N.S., and DeWiest, R.J.M., 1966, Hydrogeology, John Wiley and Sons., p. 463, Inc. New York.

Doğan, N., 2015, Kayseri Bölgesi Su Kaynaklarının Radyoaktivite İçeriğinin İncelenmesi, DSI Teknik Bültenleri, Sayı 118, Sayfa 22-34.

Gören E., 2011, Adana İçme Sularında Tridyum Aktivitesinin Belirlenmesi, Yüksek Lisans Tezi, Çukurova Üniversitesi, Fen Bilimleri Enstitüsü, Adana.

Gültekin, F. ve Dilek, R., 2005, Gümüşhane Yöresi Mineralli $\mathrm{Su}$ Kaynaklarının İz Element ve Radyoaktivite İçerikleri, Jeoloji Mühendisliği Dergisi 29 (1).

ITS, 2001. Institution of Turkish Standards, Annual Progress Report Gören, 2011 den alınmıştır.

IAEA 1989, (International Atomic Energy Agency), Measurement of Radionuclides in Food and The Environmental, Viena.

Kopya, Y., 2009, Doğu Karadeniz Bölgesinde Doğal Kaynak ve Maden sularında Radyoaktiflik Tayini, Doktora Tezi, KTÜ, Fen Bilimleri Enstitüsü, Trabzon. 
Osmond, J.K., Ivanovich, M., 1992, Equilibrium-series disequilibrium. In: Ivanovich, M. (Ed.), Applications to the Earth Marine and Environmental Sciences. Clarendon Press, Oxford.

Özger, G., 2005, Yumurtalık ve Pozant1 bölgelerinin doğal radyoaktivite düzeylerinin belirlenmesi, Yüksek Lisans Tezi, Çukurova Üniversitesi, Fen Bilimleri Enstitüsü, Adana.

TS-9130, Türk Standartları Enstitüsü, Ankara, $13 \mathrm{~s}$.

Şahinci, A., 1991, Doğal suların jeokimyası, 548 s., Reform Matbaası, İzmir.
WHO, 2003. Guidelines for Drinking Water Quality, 3rd. ed., Radiological Quality of Drinking, World Health Organization, Genova, Switzerland.

WHO, 1993, Guidelines for Drinking-Water Quality Recommendations. World Health Organization Geneva, , Gören, 2011 den alınmıştır.

World Health Organization, 1978, Radiological Examination of Drinking Water, (Copenhagen: WHO), Agbalagba, Avwiri and Chadumoren, 2013 den alınmıştır. 